\title{
LIBRARIES FOR THE PATIENTS IN HOSPITALS FOR THE INSANE.
}

\author{
BY EDITH KATHLEEN JONES, \\ Librarian at McLean Hospital, Waverley, Mass.
}

Some sort of medical library in the modern hospital for the insane is an understood thing and must be carried on along fairly conventional lines, but the organized central library for the use of the patients is a comparatively new idea and presents several problems peculiar to itself.

In order to find out how the various hospitals are meeting these problems and how far the organized library is superseding the old plan of bookcases on the wards, a circular letter was sent from McLean Hospital to 120 of the largest and most representative institutions of the kind in this country and in Canada. Answers were received from 95 ; adding for statistical purposes McLean itself, we have a basis of 96 hospitals and asylums from which to draw our conclusions. Of these 96 , there are only 15 which have no books at all. The superintendents of several of these latter hospitals deplore the fact, most of them giving the illiteracy or the destructiveness of their patients as the cause; one speaks of lending his own books ; two frankly state that they do not believe in libraries in such institutions. Twenty-one more hospitals have no central library, but report books on the various wards ranging in numbers from 50 to 5000 volumes. Several of these superintendents write that they would prefer a central library and hope to have it in the near future, but one states that he thinks the books do more good on the wards where the patients can have access to them at all times, and two have abandoned the central library for the old ward bookcases. Many of these ward-libraries seem to be somewhat in the nature of " traveling libraries," thus obviating in a measure the chief objection to them-their sameness. Two hospitals in one city speak of Carnegie libraries so near that they depend altogether upon them and are not obliged to have books of their own as they otherwise might. 
The remaining 60 institutions report central libraries, 39 of them classified and catalogued, and others undergoing the process now or hoping to before long. Fifteen of them have librarians, of whom at least 6 seem to combine other duties. Of these 60 central libraries, 9 are maintained by regular annual appropriations of from $\$ 50$ to $\$ 500$, one is a memorial library, 6 are supported from the income of funds invested for the purpose, and the rest are provided for from maintenance or amusement funds. Only 7 of these hospitals date their libraries prior to 1880 ; the rest have all been organized within the last thirty years. McLean Hospital library leads in seniority, having seventy-five years behind her, and as would be natural with such maturity, has the largest number of volumes6700. The library of the State Homeopathic Hospital at Middletown, New York, founded in 1878 , is a close second, reporting 6600 volumes, with a circulation last year of 13,336 to McLean's 8,639. It is only fair to state, however, that the New York hospital has nearly ten times as many patients as the one in Massachusetts.

It is interesting to note that in Minnesota the libraries of the State hospitals are under the care of the State Library Commission, while in Iowa the "Board of Control" has sent out travelling librarians for the purposes of organization and supervision. These plans seem so very good that one wonders they have not been adopted in other states; perhaps they have, but these are the only ones mentioned.

Of these 60 hospitals supporting central libraries, not more than one or two seem to have been able to achieve what is in many ways the ideal-the separate building devoted exclusively to stacks and reading rooms, open every day to the patients and employees-in fact a public library for private uses. The rest of them are housed in the administration building or in special rooms set apart for the purpose in some ward-and these are the ones which have to solve their own problems of administration and adapt themselves to existing conditions.

Coming from a public or a college library into one belonging to a hospital, one is immediately struck with the wholly different atmosphere. In the first place, the collection of books is formed, not for instruction but for entertainment; it is a therapeutic, not an educational factor. It is an outgrowth of the old ward bookcases and may be compared to the private library of a gentleman of 
means and culture, leaning largely in his tastes to fiction, literature, travels and fine arts. Again, while in a public or a college library quietness is insisted on and conversation prohibited, in a hospital it is the aim to make of the library a pleasant recreation room and of the librarian a hostess as well as an official. It is a little difficult to combine the two qualities when one is charging from fifty to eighty books an hour, nevertheless it does depend very largely upon the personality of the librarian and the atmosphere she is able to create whether the patients will come to the library to any great extent.

These, then, are the conditions under which the hospital library must be developed: the desirable features of the home-like private library must be preserved, and all machinery of administration must combine efficiency with unobtrusiveness. Open shelves are a necessity, as the patient must be allowed to browse at will. Rules should be few and elastic, and cataloguing, classification and charging system simple and easily understood. For this last, after experimenting with several different kinds of charging systems at McLean and finding them too cumbersome for our needs or entailing more labor on the part of the librarian than seemed commensurate with results, we have reduced our impedimenta to four thingsa pocket pasted in the back of the book for the date, a book card in it on which to write the borrower's name, a date stamp and a charging box-and we find them amply sufficient. The card (which it is unnecessary to stamp) will show at a glance who has had the book and the librarian will thus avoid sending the same book twice to the same person, while she can be sure that a new book has been on all the wards before the employees are allowed to have it. Getting the books back again, not only from the patients but also from the employees, is often a work of time and patience, for there are no fines (though in some hospitals failure to return a book promptly entails loss of privilege), and the borrower is frequently disposed to consider the borrowed book as his own property, thus carrying out still further the idea of the private library.

In regard to classification, the Dewey is probably the simplest for the purpose, but if necessary, tamper with him and bend him to your needs. With the first change one feels much as when, a small child, he first omitted to say his prayers; but as in that case, 
though much to his surprise, nothing happened, so in this the library does go on, and the only appreciable difference is an increased facility for placing one's books where one wants them. I might mention in my own library the grouping under 796-799 of all out-door essays, " nature studies," animal stories, mountainclimbing and the like, which were scattered broadcast through 810,820 and 500 ; the changing of $750-759$ into schools of painting with history numbers (75I American, 752 English, 753 German, etc.), and above all a complete rearrangement of 900-913 and 920 by which archaeology is 900-909, geography 910-912, travels 913919 , and history 920 on-making a much more consecutive order on the shelves and one more comprehensible to the uninitiated.

Upon one point nearly all the hospitals quoted above seem agreed: that the central library should not entirely supersede the old idea of books on the wards, and that especially there should always be some books and magazines on the wards for excited patients, even though they are soon destroyed. The plan used at McLean Hospital seems essentially the one generally in vogue elsewhere. The wards are made a sort of clearing-house for duplicates, old sets replaced by better editions, volumes too far gone for binding, old bound magazines, and books so out of date that no one cares to draw them from the library but which help to pass away the time on the wards or in the recreation rooms. In this way the central library is relieved from over-crowding and the ward bookcases furnish plenty of books which the patients may always have at hand. As for magazines, the weeklies may be circulated among the wards, ending with those for the excited patients. The monthly magazines may be sent out in the same way, but returned to the library before reaching these wards; one copy of each of the "big four," as some one has called them, may then be kept for binding, and the others distributed among the more destructive patients.

No library, however wisely selected and carefully organized, can run itself. Without intelligent management it will soon relapse into a mere collection of books, absolutely valueless for all purposes of helpfulness. The old idea that anyone who can read and write is eligible for the position of librarian is happily obsolete in the public library, and apparently is fast becoming so in the hospitals, which are beginning to recognize the fact that on the person- 


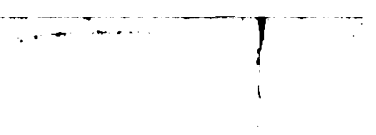

ality and ability of the librarian depends, to a great degree the success of this department. It is an interesting fact that of the two hospitals which have abandoned the central library idea neither had or has a librarian. In truth, the librarian in a hospital should have not only all the qualifications needed in an ordinary library, but she should unite in even greater degree the wisdom of the serpent with the harmlessness of the traditional dove. She ought to possess a considerable amount of tact, for she will come into more intimate and personal relations with her readers than does the average public librarian, and she must never forget that her first duty is to make her department helpful to the patients. The latter must be made to feel perfectly at home and must be allowed to misplace books if they please and take out as many (within reason) as they desire. Nevertheless they must be gently disengaged from more than one new book of fiction at a time, and if they are careless or destructive their attention must be diverted from the more costly art books to the cheaper picture books. On the other hand friendly overtures must be made to the timid and self-deprecatory, and the part of "Discourager of Hesitancy" enacted toward the vacillating and inadequate. Moreover, the librarian must have a good memory for books and be able to estimate a patient's taste, for many of them will depend entirely upon her to select their reading. They all want "good, clean, absorbing stories "; nevertheless one likes them in detective form, another in short stories; one will read only English novels, another leans to wild west cow-boy fiction while still another wishes only love stories; the librarian is expected to remember which sort to give which persons. Then, too, a physician will desire that a certain type of book be sent to a certain patient, and the librarian must know where to find it.

Above all things, the hospital librarian should be capable of selecting her own books. She should be a good critic and be personally sure that the fiction she buys is wholesome and "good literature." To her should be intrusted the expenditure of the appropriation, and she should be able to spend it wisely, keeping within its limits yet making it come out even-for the few dollars saved one year "can never come back again" to offset the few dollars overdrawn another. She must always keep in mind that the users of her library are in the hospital for recuperative, not educational, 
purposes, and that seventy-five per cent of the books called for will be fiction; therefore she will not yield to the temptation to build up her department with books so solid no one will look at them-neither will she allow her garden of books to run entirely to flower. The few more solid things she cannot resist buying for the honor of her library she can judiciously send to the wards as "traveling libraries" in the hope that someone may be attracted by a book under his hand that he never would trouble to draw for himself. These "traveling libraries," composed of some halfdozen volumes on different subjects and loaned successively to the sitting-rooms on each ward for the less excited patients, form one of the best ways of reaching those patients who will not come to the library and lack the initiative to take any steps toward entertaining themselves. Such a system has been in practice with great success at McLean for two or three years, and other hospitals speak of it as in vogue in their various departments.

The librarian in a hospital certainly has a wide field of usefulness. Not only has she the patients' library under her charge, but in most of the larger hospitals carried on according to modern ideas, she will also have a medical department to look after, with its ordering, cataloguing, binding, etc., and its foreign periodicals demanding at least a working knowledge of French and German. McLean Hospital has five thousand volumes in this department, and takes eighty-four medical and scientific periodicals. Furthermore, she will probably be expected to file hospital reports, type and file name and diagnosis cards for the case-records, and if she writes a good "library hand," do any printing and labeling which may be needed. In the smaller hospitals she usually will be required to combine the duties of librarian with those of stenographer or clerk. She does many things outside of ordinary library work, and I can think of but one department where less is required of her than of her public library sister-she is not held responsible for forming the reading morals of the public school child! Yet if, sometimes, she feels that, like the immortal hero of the "Nancy Bell," she is

$$
\text { " a cook and a captain bold, }
$$


it is, after all, most interesting work and not in the least monotonous, and it has its compensations.

In the very pleasant and suggestive personal letters which accompanied many of the cordial responses to our circular, the superintendents of these various hospitals speak particularly of the great benefit of their libraries as a therapeutic agent, and of the importance of having trained librarians in connection with them, in order not only that the work may be more systematically carried on, but because of their more intelligent co-operation with the physicians in the selection of books best suited to the mental condition of the patients. Although but one $\operatorname{cog}$ in the vast machinery of the modern hospital, yet the library seems generally to be considered rather an important $\operatorname{cog}$ and one whose value cannot be estimated in dollars and cents or in the number of its volumes. 